\title{
Ledarskap för hållbar omställning i högre utbildning
}

\author{
John Holmberg \\ Avdelningen för fysisk resursteori, Chalmers tekniska högskola
}

\begin{abstract}
FN:s ledning är tydlig med att Agenda 2030 kräver transformativt och inkluderande ledarskap. Ett ledarskap som kräver att vi tar modiga beslut och flyttar oss ut ur våra "comfort zones” och välkomnar innovativa sätt att arbeta och tänka. I denna artikel ger jag min reflektion över ledarskapskompetenser i undervisningen och ledarskapets betydelse inom undervisningsorganisationen för att möjliggöra för studenter att bygga sådana kompetenser samtidigt som de skapar värde för andra. Det handlar om ledarskap på olika nivåer: att leda sig själv, att leda ihop med andra och att leda för det gemensamma globala samhället. Det handlar också om att skapa rum/utrymme för att möjliggöra utforskande samverkan för hållbar omställning. Att skapa detta förändringsutrymme kräver dock att ledningen, speciellt inom utbildningsystemet, förstår att skilja på men ändå ser det ömsesidiga beroendet av två logiker för styrning och utveckling: kryssnings- respektive expeditionslogiken.
\end{abstract}

Nyckelord: Lärande, hållbar utveckling, systeminnovation, expedition, ledarskap

\section{BAKGRUND}

I en annan text i detta specialnummer gav jag min reflektion över hur FN:s processer för lärande för hållbar utveckling och högskolor och universitet (här förkortat till HoU) kan bli mer aktiva i omställning till en hållbar framtid samt hur studenter kan vara möjliggörare i HoU:s olika roller (Holmberg, 2020). I samma text nämnde jag även frågan som väcktes vid $\mathrm{FN}$ :s avslutande konferens för årtiondet för lärande för hållbar utveckling (DESD) i Aichi-Nagoya 20I4: "Behöver HoU uppdatera sitt övergripande uppdrag?” Förslaget som framfördes var att uppdraget bör revideras till att bidra till hållbar utveckling snarare än till utveckling i allmänhet. Agenda 2030 ger tre nyckelord som kan utgöra stöd för att diskutera ett sådant bidrag:

(i) Transformation (omställning) utifrån insikten att marginella förändringar inom rådande system och strukturer inte förmår att hantera de stora samhällsutmaningarna;

(ii) Integration (samverkan) utifrån insikten att när vi arbetar med systemförändringar behöver olika perspektiv integreras och vi behöver ha alla relevanta perspektiv integrerade $\mathrm{i}$ arbetet från början, vilket är en utmaning eftersom vår vana är att dela upp problem i delar och lösa delarna. Dessutom har ingen enskild aktör rådighet över en systemomställning, som därför ofta kräver nya former av samverkan. Det behövs alltså även en integration av olika aktörsgrupper i arbetet. Detta är en utmaning eftersom vi under lång tid har byggt silostrukturer inom och mellan organisationer.

(iii) universalitet utifrån insikten att de flesta av de stora samhällsutmaningarna är globala i sin karaktär, vilket innebär att om lokala lösningar ska vara hållbara måste de vara del av de globala lösningarna.

*Författarkontakt: John Holmberg, john.holmberg@chalmers.se

Artiklar och reflektioner är kollegialt granskade. Övriga bidragstyper granskas av redaktionen. Se https://hogreutbildning.se ISSN 2000-7558

(C)2020 John Holmberg. This is an Open Access article distributed under the terms of the Creative Commons Attribution-NonCommercial 4.0 International License (https://creativecommons.org/licenses/by-nc/4.0/), allowing third parties to share their work (copy, distribute, transmit) and to adapt it, under the condition that the authors are given credit, that the work is not used for commercial purposes, and that in the event of reuse or distribution, the terms of this license are made clear.

Citation: Holmberg, J. (2020). "Ledarskap för hällbar omställning i högre utbildning», Högre utbildning, 10(1), 98-107. https://doi.org/10.23865/ hu.v10.2422 
Slutrapporten för DESD lyfter ledarskapet på alla nivåer som det viktigaste för att få till det lärande för hållbar utveckling som världen så desperat behöver (UNESCO, 20I4). Det finns en omfattande och växande litteratur om ledarskapets betydelse i omställningsprocesser, se t.ex.: transformational leadership (Ackoff, 1999), systems leadership (Senge m.f., 20I5), complexity leadership (Uhl-Bien m.fl., 2007), self-leadership (Stewart m.fl., 20II), regenerativ leadership (Hardman, 20IO) och sustainability leadership (Ferdig, 2007). Denna text reflekterar över ledarskapet för hållbar omställning från två perspektiv: Studentens perspektiv, d.v.s. vilka ledarskapskompetenser behöver studenten ges utrymme att utveckla samt utbildningsorganisationens perspektiv, d.v.s. vilken typ av ledarskap möjliggör för studenten att utveckla dessa kompetenser.

Utgångspunkten är att samtidigt som ledarskap lyfts som så avgörande för hållbar omställning saknas ledarskapsförmågor i kompetensramverken för lärande för hållbar utveckling, e.g. (Wiek m.fl., 20II), och ledarskap nämns inte heller i den senaste forskningsagendan för det internationella forskarnätverket för omställningsforskning (Köhler m.fl., 20ı9).

Högre utbildning är till stor del fortfarande organiserad på ett envägs, hierarkiskt och reproduktivt sätt i förhållande till lärandet och innehållet är ofta disciplinärt uppdelat med bristande helhetsperspektiv (Wals \& Corcoran, 2006). Det finns alltså skäl att reflektera över ledarskapskompetenser, försöka fånga hur studenter utvecklar dessa på bästa sätt samt bygga lärandemiljöer som möjliggör för studenten att utveckla dem kopplat till hållbar omställning.

Att utbilda och kompetensutveckla på alla nivåer för en hållbar utveckling är naturligtvis extremt viktigt, men det är ändå bara en del av det lärande som måste till i arbetet med Agenda 2030. Alla verksamheter som möter nya komplexa samhällsutmaningar, inklusive universitet och högskolor, behöver ompröva sin verksamhet för att finna nya mer framgångsrika vägar. Det handlar om att bygga och leda lärande organisationer. Innan jag går djupare in i ledarskapskompetenser för studenter respektive ledarskap inom grundutbildningsorganisationen utvecklar jag först några tankar om två logiker för ledarskap och förändringsprocesser.

\section{KONSTEN ATT SKILJA MELLAN TVÅ LOGIKER FÖR LEDARSKAP OCH FÅ DEM ATT STÖDJA VARANDRA}

Bateson (I972) skiljer på fyra nivåer av lärande, där den fjärde nivån inte existerar i praktiken. Winter m.fl. (20I5) har benämnt de tre första nivåerna som: conformative (att göra saker bättre); reformative (göra bättre saker) samt transformative (se saker på ett annat sett). Många forskare grupperar ihop den andra och tredje nivån och tänker på lärande organisationer som en dikotomi. Argyris och Schön (1974) uttrycker denna dikotomi som enkel- respektive dubbelloop-lärande. Enkel-loop-lärande sker när ett fel upptäcks och åtgärdas utan att ifrågasätta eller ändra underliggande antaganden om vad som styr handlandet. Dubbel-loop-lärande sker när problem hanteras genom att undersöka och ändra underliggande antaganden och styrmodeller. Det finns flera andra benämningar på denna typ av dikotomi: lägre nivå- och högre nivålärande (Fiol \& Lyles, 1985); första och andra ordningens lärande (Arthur \& Aiman-Smith, 200I); marginell och radikal förändring (Miner \& Mezias, 1996) och anpassat och generativt lärande (Senge, 1990). När organisationer står inför större yttre förändringar menar dessa forskare att det som motsvaras av dubbel-loop-lärande är nödvändigt. Denna slutsats sammanfaller väl med innebörden av de tre nyckelorden i Agenda 2030 som beskrevs ovan och konstaterandet på första sidan av "transforming our world" (United Nations, 2015): "bold and transformative steps ... are urgently needed to shift the world on to a sustainable and resilient path".

Det finns starka kopplingar mellan lärande organisationer och forskningsfältet "hållbar omställning" (sustainbility transition research; Köhler m.fl., 20ı9; Markard m.fl., 20ı2; Rotmans m.fl., 


\section{John Holmberg}

200I). Forskningsfältet studerar systeminnovation, som innebär grundläggande förändringsprocesser, där ohållbara system fasas ut för att ge plats åt mer hållbara system. Det kan exempelvis gälla energi-, transport-, mat- eller sjukvårdsystem. Denna typ av omställning är ofta långsiktig, komplex och involverar många intressegrupper och perspektiv (Elzen \& Wieczorek, 2005). Att navigera och leda sådan omställning är förknippat med experimenterande och lärande. Omställningslitteraturen kontrasterar systemoptimering med systeminnovation (jämför med enkel- och dubbel-loop-lärande ovan). Att optimera och förfina existerande system följer en annan logik jämfört med experimenterande (March, 199I). Därmed blir också ledarskapet av en annan karaktär för de två logikerna. Metaforiskt kan vi kalla den förra för en kryssningslogik och den senare för en expeditionslogik (Holmberg \& Larsson, 20I8; Holmberg, 2019).

Så länge en organisation kan arbeta på utan större yttre utmaningar eller förändringstryck fungerar kryssningslogiken och det mesta kan skötas med existerade styrsystem, med en känsla av kontroll. När en organisation närmar sig oseglade vatten av nya utmaningar och yttre förändringstryck (t.ex. kravet på hållbar omställning) kan det vara begåvat att skicka iväg en expedition för att pröva nya vägar istället för att äventyra hela kryssningen, i syfte att minimera risk och maximera lärandet. Engeström (20I4) uttrycker det som "Learning what is not yet there". Tabell I visar några skillnader mellan de två logikerna.

Tabell I: Skillnaden mellan kryssnings- och expeditionslogiken (Holmberg, 20Ig)

\begin{tabular}{|c|c|}
\hline Kryssningen (pågående verksamhet) & Expeditionen \\
\hline $\begin{array}{l}\text { Rådande rutiner, strukturer, budgetramar } \mathrm{mm} \text {. ger stöd åt } \\
\text { verksamheten }\end{array}$ & $\begin{array}{l}\text { Rådande rutiner, strukturer, budgetramar } \mathrm{mm} \text {. hindrar } \\
\text { expeditionen }\end{array}$ \\
\hline $\begin{array}{l}\text { Arbetet går huvudsakligen ut på att effektivisera och opti- } \\
\text { mera rådande system }\end{array}$ & $\begin{array}{l}\text { Expeditionen behöver tänka bortom och utmana rådande } \\
\text { system }\end{array}$ \\
\hline Mål, styrning och kontroll är viktiga & $\begin{array}{l}\text { I expeditionen är det snarare vägledande principer, tillit och } \\
\text { att skapa utrymme för förändring som är viktigt }\end{array}$ \\
\hline Stor vikt läggs i att mäta och följa upp & $\begin{array}{l}\text { I expeditionen är istället lärandet i centrum. Även lärandet } \\
\text { av misstag! }\end{array}$ \\
\hline Organisationen är i centrum för ledarskapet och beslut & $\begin{array}{l}\text { I expeditionen är istället frågan i centrum. Ofta utforskas } \\
\text { frågan ihop med aktörer från andra organisationer. Facilite- } \\
\text { ringförmåga är viktigare än beslutskraft }\end{array}$ \\
\hline $\begin{array}{l}\text { Handlar ofta om att lösa problem och implementera lös- } \\
\text { ningar. Ta bort något oönskat }\end{array}$ & $\begin{array}{l}\text { Handlar om att möjliggöra något nytt och annorlunda. } \\
\text { Skapa något önskat }\end{array}$ \\
\hline
\end{tabular}

Det är inte frågan om att ersätta kryssningslogiken med expeditionslogiken. Båda behövs, men har olika syften och arbetssätt. Inom näringslivet är det självklart att man måste klara att både tjäna pengar på det existerande (kryssning) och förbereda sig för det nya (expedition). Organisationer som har förmåga att klara båda logikerna samtidigt brukar benämnas ambidextra (O'Reilly \& Tushman, 20I3). Forskningen visar att om det nya görs helt isolerat från det existerande, så tar inte kryssningen vara på lärandet som sker i expeditionen, och om det nya helt integreras i det existerande så ges inte expeditionen bra förutsättningar att utforska och lära, den drunknar i den existerande logiken. Det verkar vara viktigt att hålla de två logikerna åtskilda (skapa ett rum för expedition) men att se till att kopplingen sker på högsta nivå (Smith \& Tushman, 2005). Om så sker, är expeditionen önskad av kryssningen och ges rätt förutsättningar att lyckas samtidigt som det är angeläget för expeditionen att återföra lärandet till kryssningen. 
Det är även väsentligt att inse att vi själva är en del av det system som ska förändras. Enligt Morita (japansk psykoanalytiker samtida med Freud) brottas var och en av oss med de motstridiga krafterna att söka trygghet och komfort respektive att ha modet att utforska och utvecklas (jämför kryssnings- och expeditionslogikerna ovan). I många organisationer, speciellt i de där upplevelsen av brist på tillit och känslan av att vara kontrollerad är stor, är det få som vågar riskera att göra fel. Det är alltså ledningens uppgift att skapa rum inom organisationen för expeditioner runt angelägna frågor, där det är tillåtet att göra misstag så länge man lär sig av dem.

\section{RUM/EXPEDITIONER FÖR HÅLLBAR OMSTÄLLNING INOM HOU MED EXEMPEL FRÅN CHALMERS}

HoU har en avgörande roll för en hållbar utveckling (se Holmberg, 2020) för en fördjupning. Många hållbarhetsexperter menar att om vi ska hinna ställa om samhället i tid behöver det ske under dagens studenters yrkesverksamma tid. Utöver utbildning är forskning, nyttiggörande och campusutveckling också viktiga uppgifter för HoU:s hållbarhetsarbete (Cortese, 2003). HoU behöver expandera sina ambitioner, förmågor och aktiviteter för att ta sig an större samhällsutmaningar och systeminnovation tillsammans med andra aktörer i samhället (Cortese, 2003; Trencher et al., 2014; UNESCO, 2014; Mcmillin \& Dyball, 2009). Detta kommer att kräva expeditioner på oseglade vatten och modet att ta risk och även att våga göra misstag ihop. I sådana expeditioner behöver forskningen utvecklas i riktningen mot transdisciplinaritet; nyttiggörande och innovation behöver utvecklas mot mer hållbarhetsdriven systeminnovation; och framförallt behöver utbildningen utvecklas mot mer öppna lärandemiljöer där verkliga problem hanteras ihop med externa samhällsaktörer.

Denna typ av expeditioner hindras ofta av trögheten i rådande strukturer och värderingar. Det kan gälla rankingsystem och incitamentsstrukturer för enskilda forskare, upparbetade kanaler för samverkan och traditionella idédrivna innovationssystem samt cementerade utbildningsstrukturer. Det gäller naturligtvis även rådande styr- och ledningsmodeller, t.ex. New Public Management (Bessant m.fl., 20I5).

Chalmers har haft obligatorisk undervisning inom miljö och hållbar utveckling sedan 1985 och hade fram till 2006 satsat Ioo miljoner av sina stiftelsemedel för att inrätta 7 nya professorer inom hållbar utveckling och blivit medlem i Alliance for Global Sustainability (AGS) tillsammans med ETH, Zürich, MIT, Boston, Tokyo University. År 2006 startade också ett treårigt projekt för lärande för hållbar utveckling kopplat till en nyinrättad UNESCO-professur. En viktig förutsättning för Chalmers arbete med hållbar utveckling har varit det rum för nätverkande och samverkan som startade 1989 och som idag har namnet Göteborgs centrum för hållbar utveckling. Vi kunde konstatera tre viktiga beståndsdelar för ett lyckat arbete med hållbar utveckling inom Chalmers: (i) skapa ett neutralt rum/organisation som tar ansvar för det som ofta är allas angelägenhet men ingens ansvar och som är öppet, inbjudande, spänner över silostrukturer för att undvika inlåsningseffekter, serviceorienterat (inte bygga egna imperier), bygger förtroende, sänker hinder och håller minnet i förändringsprocessen; (ii) bygga på individuellt engagemang och involvering (bottom-up), eftersom universitet, med sina kärnvärden av skepsis, nyfikenhet och yttrandefrihet, har en hög grad av autonomi som måste respekteras i en förändringsprocess; (iii) kommunicera ett tydligt engagemang från ledningen så att förändringsprocessen är i linje med universitetets övergripande vision och strategi och inte motverkas av olika incitamentsstrukturer i organisationen (Holmberg m.fl., 20I2).

När Karin Markides tillträdde som ny rektor 2006 var ambitionen tydlig att fortsätta att stärka Chalmers förmåga att bidra till hållbar omställning. Under den nya visionen Chalmers för 


\section{John Holmberg}

en hållbar framtid inrättade Markides tre vicerektorer, s.k. "initiativrektorer" (varav jag var en) som fick i uppdrag att finna ut en ny struktur som skulle öka Chalmers förmåga att ta sig an större samhällsutmaningar genom att koppla samman intresserade forskare från olika institutioner och även med externa aktörer. Ambitionen var också att integrera utbildning, forskning och innovation i den så kallade kunskapstriangeln. Det resulterade i 8 styrkeområden och en ny matrisorganisation, i vilken de tematiska styrkeområdena löpte horisontellt över Chalmers institutioner och skapade rum för samverkan och risktagande.

När vi tre initiativrektorer sökte inspiration för att bygga den nya strukturen med styrkeområden åkte vi till Stanford där vi lärde oss att tänka mer "både och" istället för "antingen eller" och att lägga stor vikt vid att hitta de tematiska frågorna som öppnar upp perspektiv och attraherar forskare och externa aktörer att vilja medverka. Ambitionen var att kombinera samhällsrelevant forskning med långsiktigt risktagande (grundforskning). Att Chalmers lyckades bli värd för Europas största forskningsprojekt, The Graphene Flagship, för tvådimensionella materials roll i omställningen till ett hållbart samhälle är ett exempel på att detta i alla fall till viss del lyckades. Genom bygget av styrkeområden lyckades Chalmers få nästan $40 \%$ av de nationella strategiska forskningsmedel som utlystes 2009. Detta gav legitimitet och kraft internt, men skapade också problem genom att den ekonomiska drivkraften delvis kom i vägen för idén att mötas runt spännande tematiska frågeställningar och utmaningar.

Vi lyckades betydligt sämre med att integrera forskning, innovation och utbildning i den så kallade kunskapstriangeln. Det var svårt att få utbildningsverksamheten att öppna upp mot styrkeområdena. (Det var också svårt att få forskare att våga ta risk in i den transdisciplinära forskningen.) Organisationskultur inom utbildningsorganisationen och incitamentsstrukturer inom forskningen hindrade expeditioner med siloövergripande verksamhet. Det var också en utmaning att hitta en bra balans i ledningen av styrkeområdena mellan vetenskaplig legitimitet och det tjänade ledarskap som genererar engagemang underifrån. I vissa fall tenderade styrkeområdena att utvecklas till forskningsråd där man sökte forskningsmedel snarare än ett rum där man tillsammans söker angelägna frågor och idéer.

HoU:s långsiktiga förmåga att nyttiggöra kunskap avgörs också av förmågan att koppla det idédrivna nyttiggörandet med det utmaningsdrivna nyttiggörandet. Det idédrivna handlar ofta om att komma på nya produkter och tjänster, medan det utmaningsdrivna ofta handlar om att förstå hur de system måste förändras som dessa produkter och tjänster fungerar inom. Till exempel är det viktigt att nya effektiva fordon utvecklas, men det är också viktigt att vi förstår vilka krav som bör ställas på transportsystemet för att klara sociala, ekonomiska och ekologiska hållbarhetskrav. För att HoU ska bli skickliga i att kombinera dessa nyttiggörandestrategier behöver samverkan mellan $\mathrm{HoU}$ och med externa aktörer utvecklas (utan att blanda ihop rollerna).

Styrkeområdena gav Chalmers bättre förutsättningar att samverka med näringsliv och offentlig sektor i regionala kunskapskluster. Denna typ av trippelhelix-konstellationer initierades av Etzkowitz och Leydesdorff (I995) och tolkar skiftet från den dominerande näringsliv-offentlig sektorkonstellationen i industrisamhället till relationen mellan HoU, näringsliv-offentlig sektor i kunskapssamhället. Vid hållbar omställning och systeminnovation (Rotmans et al., 20or; Loorbach, 2007) kan regionala kunskapskluster, ofta utvidgade till att inkludera föreningar och samhället i stort, spela en viktig roll. HoU har en långsiktig närvaro i en region och är den enda aktören som omfattar alla tre delarna i kunskapstriangeln: utbildning, forskning och innovation. Därför kan HoU ta sig an en speciell roll i att initiera och bygga regionala kunskapskluster på ett neutralt, öppet och inbjudande sätt. 
Chalmers tog sig också an uppgiften och bjöd in regionens andra aktörer på högsta nivå vid konferensen "Global Forum" i oktober 2009. Detta ledde till en serie uppföljande möten och resulterade i förslag på fem kunskapskluster, d.v.s. rum för att ihop identifiera styrkor, vita fläckar och möjligheter att tillsammans testa framtidens lösningar (Andersson m.fl., 2oII). Ett resultat inom kunskapsklustret "Hållbara Transportlösningar" var bygget av testanläggningen AstaZero, världens första fullskaliga bana för forskning, utveckling och utvärdering av framtidens aktiva trafiksäkerhet.

Erfarenheten från hela processen av att bygga kunskapskluster i Västsverige är att det fanns ett stort engagemang, gemensamt ansvarstagande och tillit på högsta nivå, men att det på lägre nivå i de olika organisationerna inte sällan fanns brist i tillit mellan organisationer. Vi såg att initiativ som kom från annat håll inom ett kunskapskluster kunde väcka misstänksamhet och rädsla (not invented here) snarare än ses som värdefulla bidrag till helheten. Vi kunde också konstatera att etablerad industrisamverkan och innovationsverksamhet i flera fall var sluten och krävde en "neutral" aktör för låsas upp för nya impulser och aktörer. Ofta fanns den etablerade strukturen mellan en del av näringslivet och offentliga aktörer. HoU kunde i flera fall spela rollen som "neutral" aktör och öppna upp för att bjuda in fler näringslivsaktörer, samtidigt som $\mathrm{HoU}$ även direkt kunde relatera till kompetensbehov och internationell uppkoppling till vetenskapssamhället.

I Holmberg (20I4) och Holmberg (2020) beskrivs hur vi skapade Challenge Lab - where learners lead and leaders learn utifrån erfarenheten att studenter har förmågan att bygga tilllit mellan aktörer och därigenom bidra till systeminnovation - just för att de är studenter! Challenge Lab är ett initiativ där masterstudenter tar sig an hållbarhetsomställningar i samverkan med forskning, näringsliv och omgivande samhälle. Challenge Lab är därmed ett rum för utmaningsdriven systeminnovation och medskapande för en hållbar framtid (ibid.). Det rum som Challenge Lab utgör har visat sig vara ett strategiskt verktyg för regional utveckling (Larsson \& Holmberg, 2018; Holmberg, 2020).

Challenge Lab är också ett rum som ger förutsättningar för studenterna att utveckla sina ledarskapsförmågor. Inom Challenge Lab och speciellt i den förberedande kursen "Leadership for sustainability transitions" har vi delat in ledarskapsförmågorna i tre delar: förmågan att leda sig själv; förmågan att leda ihop med andra och förmågan att leda för det för det gemensamma globala samhället. Inom varje del prövar vi verktyg och möjligheter att öva ihop med problemägare i samhället. I delen "att leda sig själv" ges exempelvis möjlighet att tydliggöra sina personliga värderingar och styrkor, förmåga att anbringa flera olika perspektiv på en fråga och utmana sina antagande. I delen "att leda ihop med andra" ges möjlighet att bland annat på ett neutralt och öppet sätt leda en dialog som tar vara på värdet av olika synsätt och ser konstruktiva möjligheter i spänningsfält. I delen "att leda för det gemensamma globala samhället" används Hållbarhetsfyren (Holmberg \& Larsson, 20I8) som ett verktyg att få med alla hållbarhetsdimensioner i analysen av den önskvärda framtiden och verktyg för systemkartläggning för att fånga bakomliggande orsaker till dagens problem samt viktiga hävstångspunkter i hållbarhetsomställningen. För att stötta studenterna att jobba med komplexa hållbarhetsutmaningar tillsammans med samhällsaktörer har det varit viktigt med stöd i metoder, verktyg och övergripande processramverk för att minska osäkerhet och ge kognitivt/emotionellt stöd snarare än att lämna allt till studenterna. Dessutom har det varit viktigt för studenterna att uppleva ett eget ägarskap av sitt arbete och bygga ledarskapsförmågor "inifrån-och-ut" där läraren tar ett steg tillbaka, coachar och faciliterar snarare än kontrollerar och säger vad studenten ska göra. 


\section{John Holmberg}

Tilbury (20II) konstaterar i sin expertgranskning av processer och lärande kopplat till DESD att litteraturen är tunn när det gäller djupare kvalitativa studier som fokuserar på studentengagemang och lärandeprocesser i HoU. Detta gäller i synnerhet ledarskapsförmågor som, vilket har nämnts ovan, inte ens finns med i kompetensramverken. Vi har tidigare sett att det finns ett stort värde för studenterna att utveckla denna typ av ledarskapsförmågor (Larsson \& Holmberg, 20I8). Det finns alltså flera skäl att skapa lärandemiljöer som främjar utvecklingen av denna typ av ledarskapsförmågor. Holmén m.fl. (kommande) försöker beskriva bakomliggande och viktiga (och troligen överförbara) mekanismer som fångar studenternas lärande inom Challenge Lab. Det finns ett stort utrymme för framtida forskning där mekanismer i olika lärandemiljöer diskuteras och jämförs!

\section{SAMMANFATTANDE AVSLUTNING}

Som nämndes inledningsvis faller mycket av förutsättningarna med att lyckas i arbetet med hållbar omställning tillbaks på vilket ledarskap som tillämpas. I en internationell studie som analyserade erfarenheter från 188 ledare inom HoU kunde man konstatera att det krävs ledare med visionen och kapaciteten att leda organisationen genom förändringsprocess som kan vara komplex, utdragen och osäker (Scott m.fl., 20I2). FN:s vice generalsekreterare har dragit slutsatsen att arbetet med Agenda 2030 kräver transformativt och inkluderande ledarskap. Ett ledarskap som kräver att vi tar modiga beslut och flyttar oss ut ur våra "comfort zones" och välkomnar innovativa sätt att arbeta och tänka (United Nations, 2019).

Denna text har visat på behovet av att på högsta nivå skilja på men ändå se det ömsesidiga beroendet av två logiker för styrning och utveckling: kryssnings- respektive expeditionslogiken.

I expeditioner sätts frågan i centrum och personer bjuds in från berörda aktörsgrupper. Ledarskapet handlar om att skapa rummet för utforskande samverkan, definiera den samlande frågan, bjuda in och få till en bred konstruktiv process som går bortom dagens inlåsta ohållbara system och löper över våra inarbetade silostrukturer.

En viktig del av ledarskapet är att bygga tillit inom och mellan aktörsgrupper. För att en grupp ska kunna ta sig an en komplex uppgift behöver det finnas tillit inom gruppen, annars kommer gruppen att falla tillbaks till enklare uppgifter (Wendelheim 1997). Jewell-Larsen och Sandow (1999) har illustrerat hur investering i lyssnande, dialog och vilja till fördjupad förståelse bygger tillit och hur detta lägger grunden för medskapande. De visar också hur motsatsen leder till att samma uppgifter utförs på flera håll, vilket totalt sett leder till minskade resurser, intern konkurrens och i förlängningen rädsla som motverkar medskapande. Denti (20I8) nämner även skapandet av själva handlingsutrymmet (rummet) för experimenterandet som en viktig del av tillitsbygget.

Eftersom det just är frågan om en expedition som måste tillåtas utforska utan detaljplanering och kontroll uppifrån är förmågan att förlösa engagemang underifrån ytterligare en fundamental del av ledarskapet. Self-determination theory är viktig för Challenge Lab och är en de mest spridda teorierna om inre motivation (Ryan \& Deci, 2000). Den beskriver tre förutsättningar för att inre motivation: autonomi (känslan av att inte vara styrd ock kontrollerad utan istället känna eget handlingsutrymme); kompetens (känslan av att uppgiften är avvägd i förhållande till förmågan att klara den och att man tillåts växa med uppgiften) samt sammanhang/samhörighet (känslan av att finnas i ett meningsfullt sammanhang som känns tryggt och även tillåter misstag).

Utbildningsorganisationen leds vid de flesta universitet helt enligt kryssningslogiken. Det behövs aktivt ledarskap för att få till och lära av värdefulla expeditioner, d.v.s. nya prövande 
lärandemiljöer. Ett avgörande problem är att dessa ofta inte lätt kan inordnas i de utbildningsstrukturer som finns. Om kravet är att expeditionerna måste inordnas i kryssningslogikens strukturer kommer de antingen aldrig till stånd eller så orkar de inte fortsätta. Det behövs alltså en medvetenhet om behovet av båda logikerna och en förmåga att hantera dessa samtidigt. Idag läggs för mycket ansvar på initiativtagarna till expeditionerna att också finna förutsättningar för expeditionen. Ett bra ledarskap inom utbildningsorganisationen förstår värdet av expeditioner för utvecklingen av hela verksamheten. Det är inte heller rimligt att det ekonomiska ansvaret för expeditioner som ämnar gynna hela universitetets verksamhet, och som ofta gynnas av att bjuda in studenter från många olika utbildningsprogram, läggs på en enskild institution utan centralt stöd. Kanske är det till och med så att värdet av expeditioner inom utbildningen vid landets HoU behöver uppmärksammas av utbildningsdepartementet med åtföljande öronmärkta medel ut till HoU? Här kanske Challenge Labs motto kan tillämpas: ”Think big, start small act now!"

\section{TACK}

Jag vill rikta ett särskilt tack till Johan Holmén för hans värdefulla kommentarer i arbetet med den här texten.

\section{FÖRFATTARPRESENTATION}

John Holmberg är professor i fysisk resursteori, innehavare av en UNESCO-professur i lärande för hållbar utveckling och grundare av Challenge Lab vid Chalmers tekniska högskola.

\section{REFERENSER}

Ackoff, R. L. (1999). Transformational Leadership. Strategy \& Leadership, 27(1). 6.

Andersson, G.-I., Fredman, P., Holmberg, J., Hultén, A., Markides, K., Ransgård, J., Trouvé, J. \& Törsäter, B. (2011, januari 9). Låt Västsverige bli framtidens testarena. Göteborgs-Posten.

Argyris, C. \& Schön, D. (1974). Theory in Practice: Increasing Professional Effectiveness. San Francisco, CA: Jossey-Bass.

Arthur, J. \& Aiman-Smith, L. (2001). Gainsharing and organizational learning: An analysis of employee suggestions over time. Academy of Management Journal, 44(4), 737-754.

Bateson, G. (1972). Steps to an Ecology of Mind. San Francisco: Chandler Pub. Co.

Bessant, S. E. F., Robinson, Z. P. \& Ormerod, R. M. (2015). Neoliberalism, new public management and the sustainable development agenda of higher education: History, contradictions and synergies. Environmental Education Research, 21(3), 417-432. https://doi.org/10.1080/13504622.2014.993933

Cortese, A. D. (2003). The Critical Role of Higher Education in Creating a Sustainable Future. 8.

Denti, L. (2018). Tillit och innovation.pdf. Socialmedicinsk tidskrift, 3.

Elzen, B. \& Wieczorek, A. (2005). Transitions towards sustainability through system innovation. Technological Forecasting and Social Change, 72(6), 651-661. https://doi.org/10.1016/j.techfore.2005.04.002

Engeström, Y. (2014). Learning by Expanding: An Activity-Theoretical Approach to Developmental Research. Cambridge: Cambridge University Press. doi:10.1017/CBO9781139814744

Etzkowitz, H. \& Leydesdorff, L. (1995). The triple helix - university-industry-government relations: A laboratory for knowledge-based economic development. EASST Review, 14, 14-19.

Ferdig, M. A. (2007). Sustainability Leadership: Co-creating a Sustainable Future. Journal of Change Management, 7(1), 25-35. https://doi.org/10.1080/14697010701233809

Fiol, C. M. \& Lyles, M. A. (1985). Organizational Learning. Academy of Management, 10(4), 803-813.

Hardman, J. (2010). Regenerative Leadership-A Model for Transforming People and Organizations for Sustainability in Business, Education, and Community, 10(5), 17.

Holmberg, J. (2014). Transformative learning and leadership for a sustainable future: Challenge Lab at Chalmers University of Technology. I P. B. Corcoran, B. P. Hollingshead, H. Lotz-Sisitka, A. E. J. Wals 
\& J. P. Weakland (red.), Intergenerational learning and transformative leadership for sustainable futures (s. 91-102). Wageningen Academic Publishers. https://doi.org/10.3920/978-90-8686-802-5_4

Holmberg, J. (2019). Oseglade vatten?-Då behövs expeditioner! I J. Algehed, E. Eneqvist, C. Jensen \& J. Lööf (red.), Innovation och stadsutveckling. Mistra urban futures. https://research.chalmers.se/ publication $/ 513888$

Holmberg, J. (2020). Högre utbildning och hållbar omställning - En reflektion över studenternas roll. Högre utbildning, 10(1), 90-97.

Holmberg, J., Lundqvist, U., Svanström, M. \& Arehag, M. (2012). The university and transformation towards sustainability: The strategy used at Chalmers University of Technology. International Journal of Sustainability in Higher Education, 13(3), 219-231. https://doi.org/10.1108/14676371211242544

Holmberg, J. \& Larsson, J. (2018). A Sustainability Lighthouse-Supporting Transition Leadership and Conversations on Desirable Futures. Sustainability, 10(11), 3842. https://doi.org/10.3390/su10113842

Holmén, J., Adawi, T. \& Holmberg, J. (kommande). Student-led sustainability transformations: Mechanisms of learning in a 'Challenge Lab' curriculum methodology.

Jewell-Larsen, S. \& Sandow, D. (1999). Personal development: The key to change acceleration in global operations. Target, 15(4), 15-20.

Köhler, J., Geels, F. W., Kern, F., Markard, J., Onsongo, E., Wieczorek, A., ... Wells, P. (2019). An agenda for sustainability transitions research: State of the art and future directions. Environmental Innovation and Societal Transitions, 31, 1-32. https://doi.org/10.1016/j.eist.2019.01.004

Larsson, J. \& Holmberg, J. (2018). Learning while creating value for sustainability transitions: The case of Challenge Lab at Chalmers University of Technology. Journal of Cleaner Production, 172, 4411-4420. https://doi.org/10.1016/j.jclepro.2017.03.072

Loorbach, D. A. (2007). Transition management: New mode of governance for sustainable development = Transitiemanagement: nieuwe vorm van governance voor duurzame ontwikkeling. Internat. Books.

March, J. G. (1991). Exploration and Exploitation in Organizational Learning. Organization Science, 2(1), 71-87. https://doi.org/10.1287/orsc.2.1.71

Markard, J., Raven, R. \& Truffer, B. (2012). Sustainability transitions: An emerging field of research and its prospects. Research Policy, 41(6), 955-967. https://doi.org/10.1016/j.respol.2012.02.013

Mcmillin, J. \& Dyball, R. (2009). Developing a Whole-of-University Approach to Educating for Sustainability: Linking Curriculum, Research and Sustainable Campus Operations. Journal of Education for Sustainable Development, 3(1), 55-64. https://doi.org/10.1177/097340820900300113

Miner, A. S. \& Mezias, S. J. (1996). Ugly Duckling No More: Pasts and Futures of Organizational Learning Research. Organization Science, 7(1), 88-99. https://doi.org/10.1287/orsc.7.1.88

O’Reilly, C. A. \& Tushman, M. L. (2013). Organizational Ambidexterity: Past, Present, and Future. Academy of Management Perspectives, 27(4), 324-338. https://doi.org/10.5465/amp.2013.0025

Rotmans, J., Kemp, R. \& van Asselt, M. (2001). More evolution than revolution: Transition management in public policy. Foresight, 3(1), 15-31. https://doi.org/10.1108/14636680110803003

Ryan, R. M. \& Deci, E. L. (2000). Self-determination theory and the facilitation of intrinsic motivation, social development, and well-being. American Psychologist, 55(1), 68-78.

Scott, G., Tilbury, D., Sharp, L. \& Deane, E. (2012). Turnaround Leadership for Sustainability in Higher education. Sydney, Australian Office of Learning and Teaching.

Senge, P. (1990). The Fifth Discipline: The Art and Practice of the Learning Organization. London: Century Business, Random.

Senge, P., Hamilton, H. \& Kania, J. (2015). The dawn of system leadership. Stanford Social Innovation Review Winter, 2015, 27-33.

Smith, W. K. \& Tushman, M. L. (2005). Managing Strategic Contradictions: A Top Management Model for Managing Innovation Streams. Organization Science, 16(5), 522-536. https://doi.org/10.1287/ orsc. 1050.0134

Stewart, G. L., Courtright, S. H. \& Manz, C. C. (2011). Self-Leadership: A Multilevel Review. Journal of Management, 37(1), 185-222. https://doi.org/10.1177/0149206310383911 
Tilbury, D. (2011). Education for sustainable development: An expert review of processes and learning. UNESCO Education sector.

Trencher, G., Yarime, M., McCormick, K. B., Doll, C. N. H. \& Kraines, S. B. (2014). Beyond the third mission: Exploring the emerging university function of co-creation for sustainability. Science and Public Policy, 41(2), 151-179. https://doi.org/10.1093/scipol/sct044

Uhl-Bien, M., Marion, R. \& McKelvey, B. (2007). Complexity Leadership Theory: Shifting leadership from the industrial age to the knowledge era. The Leadership Quarterly, 18(4), 298-318. https://doi. org/10.1016/j.leaqua.2007.04.002

UNESCO. (2014). Shaping the Future We Want: UN Decade of Education for Sustainable Development (2005-2014) : Final Report. http://unesdoc.unesco.org/images/0023/002301/230171e.pdf

United Nations. (2015). Transforming our world: The 2030 Agenda for Sustainable Development. United Nations.

United Nations. (2019, februari 9). Delivering on Sustainable Development Goals Requires Transformational, Inclusive Leadership. Amina Mohammed's keynote remarks at the 2019 World Government Summit's SDGs in Action event- "Leadership for Achieving the Sustainable Development Goals", Dubai.

Wals, A. \& Corcoran, P. B. (2006). Sustainability as an Outcome of Transformative Learning. I J. Holmberg $\&$ B. Samuelsson (Red.), Drivers and Barriers for Implementing Sustainable Development in Higher Education. UNESCO Education sector.

Wendelheim, A. (1997). Effectiveness and process in experiential group learning (Dissertation). Stockholm University, Department of Psychology.

Wiek, A., Withycombe, L. \& Redman, C. L. (2011). Key competencies in sustainability: A reference framework for academic program development. Sustainability Science, 6(2), 203-218. https://doi. org/10.1007/s11625-011-0132-6

Winter, J., Cotton, D., Hopkinson, P. \& Grant, V. (2015). The university as a site for transformation around sustainability. International Journal of Innovation and Sustainable Development, 9(3/4), 303. https:// doi.org/10.1504/IJISD.2015.071857 